\title{
The analysis of the wind potential in selected locations in the southeastern Poland
}

\author{
Krzysztof Sornek ${ }^{1,{ }^{*}, \text { Mariusz Filipowicz }}{ }^{1}$, Wojciech Goryl ${ }^{1}$, Eugeniusz Mokrzycki ${ }^{2}$, Tomasz \\ Mirowski ${ }^{2}$ and Maciej Duraczyński ${ }^{1}$ \\ ${ }^{1}$ AGH University, Faculty of Energy and Fuels, Department of Sustainable Energy Development, \\ Mickiewicza Av. 30, 30-059 Krakow, Poland \\ ${ }^{2}$ Mineral and Energy Economy Research Institute of the Polish Academy of Sciences, Wybickiego \\ Str. 7C, 31-261 Krakow, Poland
}

\begin{abstract}
This paper shows the results of analysis of the wind potential in selected locations in the southern Poland (placed in the Małopolskie, Świętokrzyskie and Podkarpackie Voivodships). The measurements and analysis of the wind resources in potential locations of the wind turbines are important part of the investment process. The statistical analysis involves the creation of histograms (e.g. histogram of the wind speed and direction) and fitting those histograms to theoretical distributions (e.g. Weilbull distributions of wind speed). Such analysis has been described and conducted using measurement data for four selected locations. Basis on the conducted analysis, the economy efficiency and environmental impact of wind turbine operation has been estimated. Three market available wind turbines have been included to calculate NPV, IRR and SPBT indicators. Then, the avoided emissions of $\mathrm{CO}_{2}, \mathrm{NO}_{x}, \mathrm{SO}_{2}$ and dust have been calculated. There were also conducted some calculation using TRNSYS simulation software. The results of simulations have been compared with measurement data and the level of convergence have been found.
\end{abstract}

\section{Introduction}

As regards the number of wind power plants, south-eastern part of Poland is the area where relatively small number of wind turbines have been installed so far. Due to the lack of detailed data concerning the potential, the observed interest of possible investors is not as high as in other parts of the country (in the north-west and in central Poland). Since the development of wind power sector depends primarily on proper location of wind farms, it is necessary to acquire and process suitable data, first of all including estimated wind power potential in certain area. Known wind power resources make it possible to carry out financial and ecological analysis of undertakings, which could be completed in selected locations.

This study involves an analysis of measurement data from four selected measurement masts located in Małopolskie, Świętokrzyskie and Podkarpackie Voivodeships. The acquired data provided the grounds for carrying out statistical analysis and identifying basic parameters characterizing the wind. Then, the following were carried out: the assessment of

\footnotetext{
* Corresponding author: krzysztof.sornek@agh.edu.pl
} 
wind power resources, and financial and ecological analysis of the investment in selected types of wind turbines. Obtained results have been compared to the results of dynamic simulations performed using the TRNSYS software.

\section{Assessment of wind parameters}

The measurements and analysis of wind resources in general can be divided into two stages: long-term data acquisition from measurement masts (primarily wind speed and direction), and their further statistical analysis.

Measurement masts are provided with devices, which generally can be divided into: sensors, recorder and auxiliary equipment. The most frequently used sensors are: wind speed sensors (e.g. cup anemometers, vane anemometers, and ultrasonic anemometers), wind direction sensors (potentiometer-type transducers), temperature sensors, and - in some cases - pressure and humidity sensors. The measurements are most often carried out at a height below planned height of wind turbine rotor axis (installation of so high mast would be very expensive and difficult due to technological reasons). As a result of this, two or more anemometers are used in order to obtain information on wind speed at different heights. In this way, it is possible to determine wind speed profile, which allows its extrapolation at required heights. Specific configuration of sensor arrangements is selected i.a. depending on terrain roughness class.

Wind speed $v$ affects the parameter called air stream power density $P$ according to the formula (1):

$$
P=\frac{1}{2} \rho v^{3},
$$

where $\rho$ is air density. Power density may be given in watts per square meter.

The first stage of statistical analysis involves developing histograms of data - wind speed and direction, depending on the duration of particular measurements (monthly, daily, etc.), and wind speed and direction depending on height. These histograms are then being fitted by theoretical distributions: statistical wind speed distributions, daily speed histograms and models of wind speed on measurement height. Wind speed histograms are most often represented using a two-parameter Weibull distribution or sometimes one-parameter Rayleigh distribution (which is a special case of the Weibull distribution). This does not illustrate precisely the frequency of occurrence of certain wind speeds. In fact, it may differ even by $30 \%$ from true distribution determined empirically [1].

\section{Results}

\subsection{Description of selected locations}

Measurement data used in the analysis of wind power potential in selected areas of Małopolskie, Świętokrzyskie and Podkarpackie Voivodeships originate from four measurement masts installed in the following locations:

- location in eastern part of Świętokrzyskie Voivodeship (north-west of Sandomierz) wind speed and direction measurement at the height of 50 and $100 \mathrm{~m}$;

- location in eastern part of Małopolskie Voivodeship (south of Gromnik) - wind speed measurement at the height of 10 and $40 \mathrm{~m}$ and wind direction measurement at the height of $40 \mathrm{~m}$;

- location in south-western part of Podkarpackie Voivodeship (south of Jasło) - wind speed and direction measurement at the height of 50 and $100 \mathrm{~m}$; 
- location in northern part of Podkarpackie Voivodeship (north of Leżajsk) - wind speed and direction measurement at the height of 50 and $100 \mathrm{~m}$;

The selected locations are shown on the map (see Figure 1).

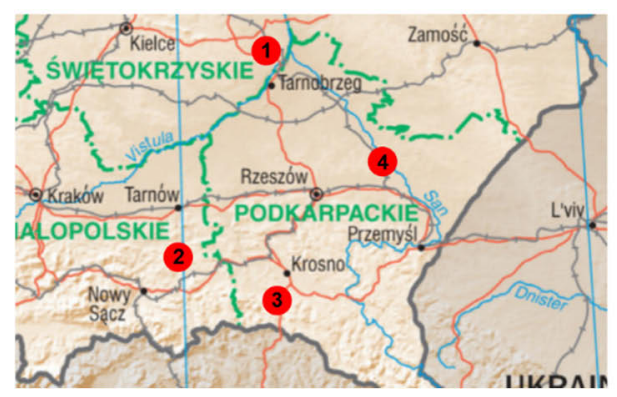

(1) - location in the vicinity of Sandomierz (Świętokrzyskie Voivodhip)

2 - location in the vicinity of Gromnik (Małopolskie Voivodhip)

(3) - location in the vicinity of Jaslo (Podkarpackie Voivodhip)

4. - location in the vicinity of Lezajsk (Podkarpackie Voivodhip)

Fig. 1. Location of data gathering masts.

The comparison presented further in this work includes data obtained directly for the height of $50 \mathrm{~m}$ in locations no. 1, 3 and 4, and data calculated for the height of $50 \mathrm{~m}$ in case of location 2 (recalculation has been carried out from the level of $40 \mathrm{~m}$ using a power model - formula 2). Moreover, the comparison of the impact of height $h$ above ground level on available wind resources $v(h)$ has been made for a given location:

where:

$$
v(h)=v_{0} \cdot\left(\frac{h}{h_{0}}\right)^{\alpha}
$$

$\mathrm{v}_{0} \quad$ - wind speed at the height of $\mathrm{h}_{0}$,

$\mathrm{h}_{0}$ - reference height,

$\alpha-$ coefficient dependent on terrain roughness.

\subsection{Comparison of wind speeds for selected locations}

The following comparisons have been made based on measured wind speeds in the selected locations: comparison of average monthly wind speed fluctuations, comparison of daily wind speed fluctuations and comparison of Weibull distributions.

\subsubsection{Comparison of average monthly wind speed fluctuations}

One of the basic aspects of wind power engineering is uneven wind speed distribution over a year. In Polish conditions, higher wind speeds appear in transition periods (spring, autumn) and in winter season, and lower speeds - in summertime. This relation is also observed in case of the discussed locations, which is shown in Fig. 2. 


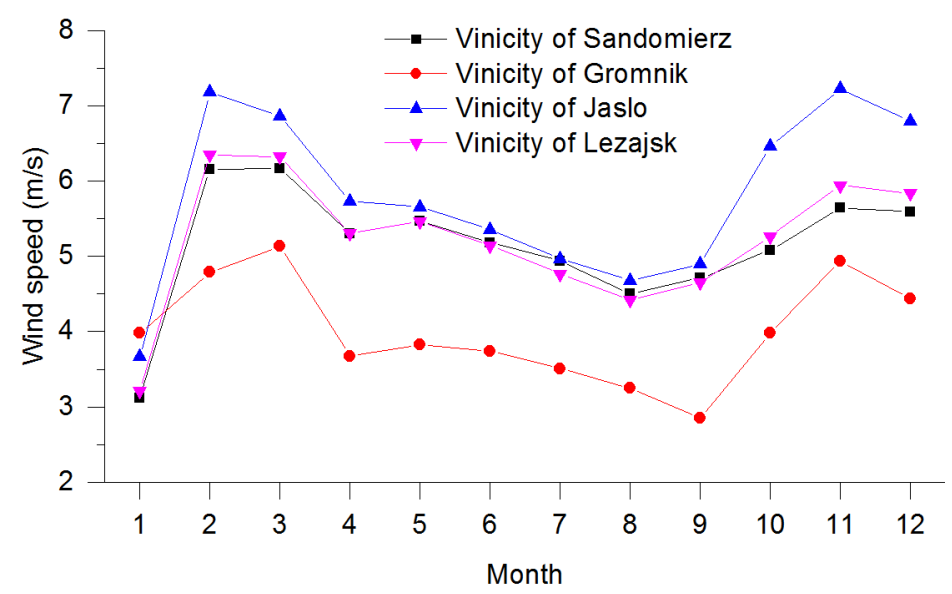

Fig. 2. Monthly wind speed profiles for selected locations.

As shown on fig. 2, the trend of changes in the average monthly wind speeds is similar. Highest wind speeds occur in February, March, November and December, and in the other months they are visibly lower. We can observe that highest average wind speeds over an entire year have been measured near Jasło, and lowest - near Gromnik. The comparison of highest and lowest average wind speeds in respective months of a year, and average wind speed over a year is presented in Table 1.

Table 1. Yearly highest, lowest and average wind speeds in selected locations

\begin{tabular}{|c|c|c|c|}
\hline Location & $\begin{array}{c}\text { Highest average } \\
\text { monthly wind speed } \\
\text { in a year } \\
\text { [m/s] }\end{array}$ & $\begin{array}{c}\text { Lowest average } \\
\text { monthly wind speed } \\
\text { in a year } \\
\text { [m/s] }\end{array}$ & $\begin{array}{c}\text { Average annual } \\
\text { value of monthly } \\
\text { wind speed } \\
\text { [m/s] }\end{array}$ \\
\hline $\begin{array}{c}\text { Vicinity of } \\
\text { Sandomierz }\end{array}$ & 6.2 & 3.1 & 5.2 \\
\hline $\begin{array}{c}\text { Vicinity of } \\
\text { Gromnik }\end{array}$ & 5.1 & 2.9 & 4.0 \\
\hline Vicinity of Jaslo & 7.2 & 3.7 & 5.8 \\
\hline $\begin{array}{c}\text { Vicinity of } \\
\text { Lezajsk }\end{array}$ & 6.4 & 3.2 & 5.2 \\
\hline
\end{tabular}

\subsubsection{Comparison of daily wind speed fluctuations}

Apart from known average monthly wind speeds, it is also possible to compare daily fluctuation of wind speeds. Wind speed profiles have been fitted using the theoretical relations adapted from works [2-3]. The formulas are based on the daily wind speed characterised by low values until early morning hours, wind speed increase from that time until late afternoon, and wind speed drop to its minimum value in the evening. Since daily wind profiles being an average of many days has been considered, fitting has been carried out with the formula 3. 
where:

$$
V=\left\{\begin{array}{c}
V_{\text {min }} t \in\left[0, T_{1}\right) \\
V_{\text {min }}+V_{\text {max }} \cdot \sin \left(\frac{t-T_{1}}{A_{1}}\right) t \in\left[T_{1}, T_{2}\right) \\
V_{\text {min }}+V_{\text {max }} \cdot \sin \left(\frac{T_{3}-t}{A_{2}}\right) t \in\left[T_{2}, T_{3}\right) \\
V_{\text {min }} t \in\left[T_{3}, 24 h\right)
\end{array}\right.
$$

$\mathrm{T}_{1}, \mathrm{~T}_{2}, \mathrm{~T}_{3}$ - individual stages of wind speed pattern variability (fitting parameters),

$\mathrm{A}_{1}, \mathrm{~A}_{2}$ - fitting parameters,

$\mathrm{V}_{\min }, \mathrm{V}_{\max }-$ minimum and maximum wind speed in a daily histogram,

$\mathrm{t}-$ current time,

$\mathrm{V} \quad-$ value of speed from theoretical fitting.

Comparison of daily wind speed fluctuations for the considered locations is provided in Fig. 3

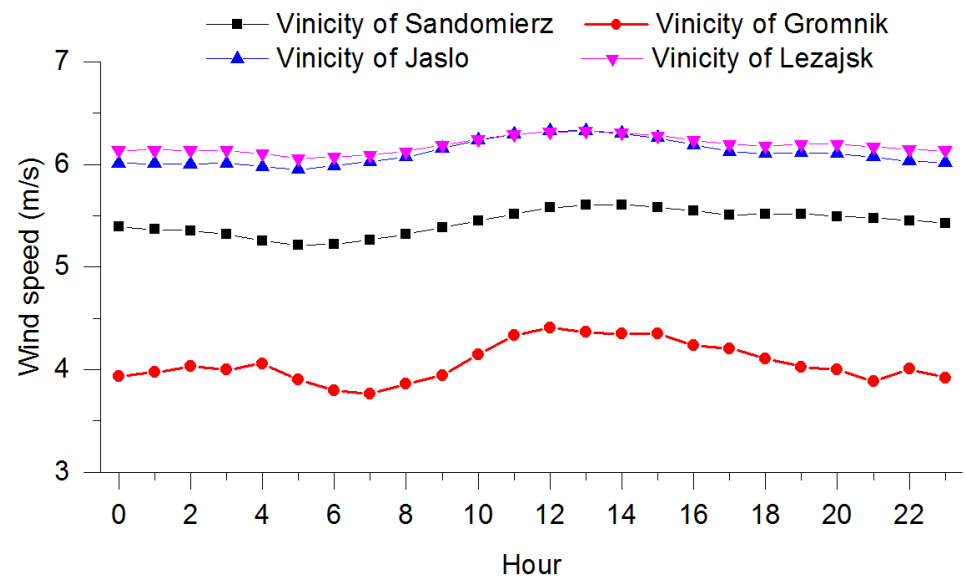

Fig. 3. Daily wind speed profiles

According to Fig. 3, daily wind speed profile is very stable for the vicinity of Sandomierz, Jasło and Leżajsk. Visibly higher daily wind speed fluctuations appear near Gromnik, where the speed changes from 3.8 to $4.4 \mathrm{~m} / \mathrm{s}$ over 24 hours.

\subsubsection{Weibull distributions}

Based on completed measurements, it is also possible to determine probability density function $\mathrm{f}(\mathrm{v})$ for the occurrence of a certain wind speed over a year. For that purpose, Weibull distributions have been specified for individual locations using the formula 4.

$$
f(v)=\left(\frac{k}{c}\right)\left(\frac{v}{c}\right)^{k-1} \cdot \exp \left[\left(-\frac{v}{c}\right)^{k}\right]
$$

where:

$\mathrm{c}, \mathrm{k}$ - fitting parameters. Parameter $\mathrm{c}$ has the function of the so-called scale parameter, which means in general that the higher value of that parameter, the wider is a given distribution. In this case, it means greater range of wind speed fluctuations at a given location. Parameter $\mathrm{k}$ is the so-called shape parameter and it affects distribution shape. Changing the shape parameter from $\mathrm{k}=1$ (and less) to higher values, we move from the category of exponential distributions to the distributions having a maximum. Parameter $\mathrm{c}$ determines with some approximation the position of distribution maximum (especially for distributions with small $\mathrm{k})$. 


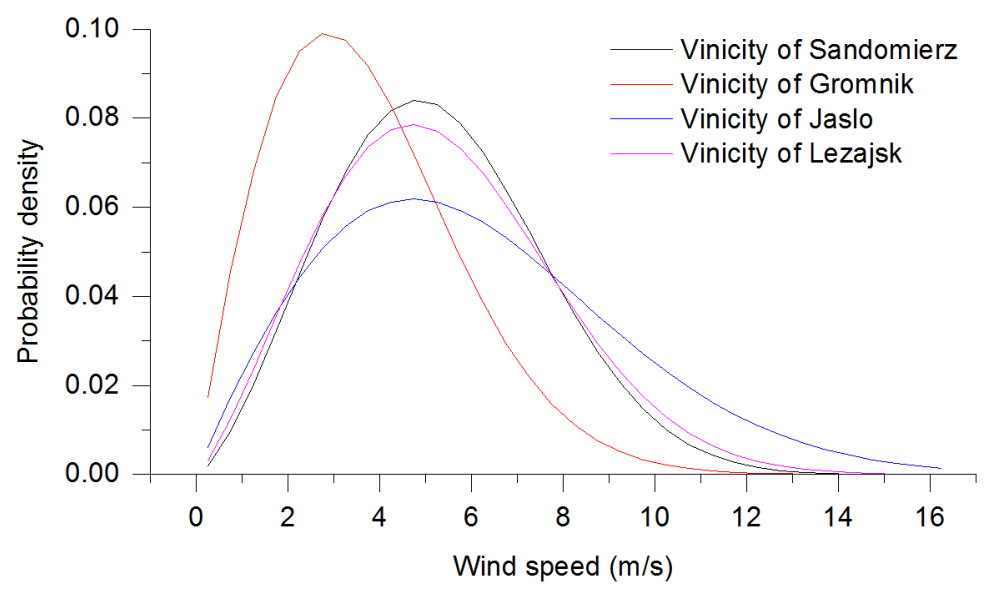

Fig. 4. Fitted Weilbull distribution of wind speed for selected location

Comparison of Weibull distributions for the selected locations shows evidently higher share of speeds ranging from 9 to $16 \mathrm{~m} / \mathrm{s}$ near Jasło than in the other considered locations. On the other hand, speeds from range $0-5 \mathrm{~m} / \mathrm{s}$ prevail near Gromnik. Then, in the vicinity of Sandomierz and Leżajsk the conditions are much the same - speeds from range $4-7 \mathrm{~m} / \mathrm{s}$ prevail in these regions. Thus, one may conclude that the vicinity of Jasło is characterised by the most favourable wind conditions among all examined locations.

\subsection{Determination of wind speeds for the considered heights}

Because wind speed is strongly dependent on the height above ground level, an additional analysis of changes in monthly and daily wind speed at the height of $100 \mathrm{~m}$ was carried out for the location near Jasło. The results obtained for the vicinity of Jasło (the location with the best wind conditions determined at the height of $50 \mathrm{~m}$ ) are shown in Figs. 5, 6 and 7.

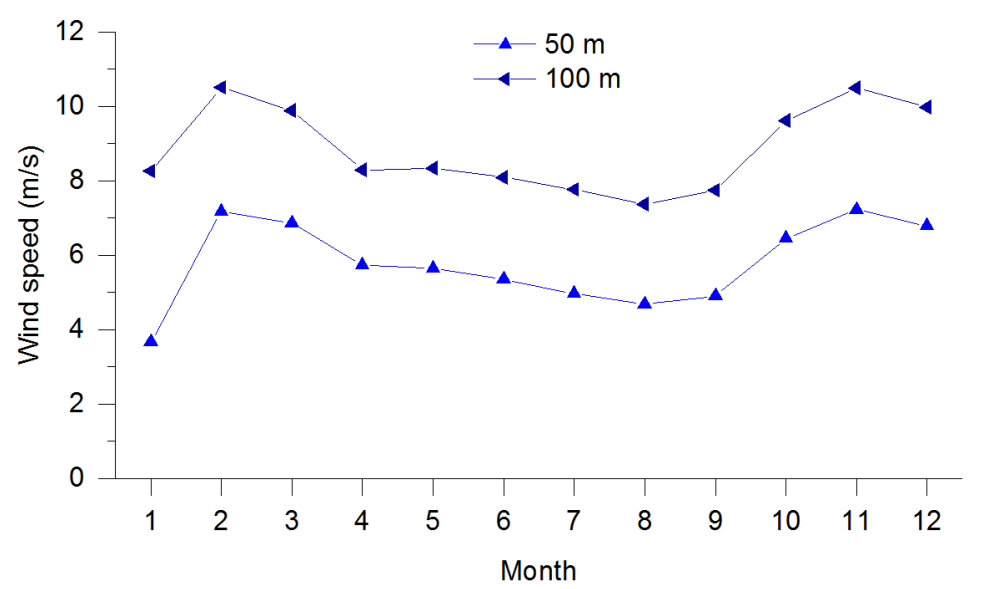

Fig. 5. Monthly wind speed profiles at two heights for Jasło.

Comparison of fluctuations of average monthly wind speeds at the heights of $50 \mathrm{~m}$ and $100 \mathrm{~m}$ shows big similarity (Fig. 6). The average difference between the values measured at both heights is ca. $3 \mathrm{~m} / \mathrm{s}$ - highest in January (ca. $4.6 \mathrm{~m} / \mathrm{s}$ ) and lowest in April (ca. $2.6 \mathrm{~m} / \mathrm{s}$ ). The situation is slightly different when we analyse daily wind speed distribution. Analysis of 
the data from Fig. 6 allows observing that the trajectory of changes in wind speed at the height of $100 \mathrm{~m}$ is less even than in the case of $50 \mathrm{~m}$ height. Moreover, average daily wind speed in the case of $100 \mathrm{~m}$ is ca. $48 \%$ higher than the speed measured at the height of $50 \mathrm{~m}$.

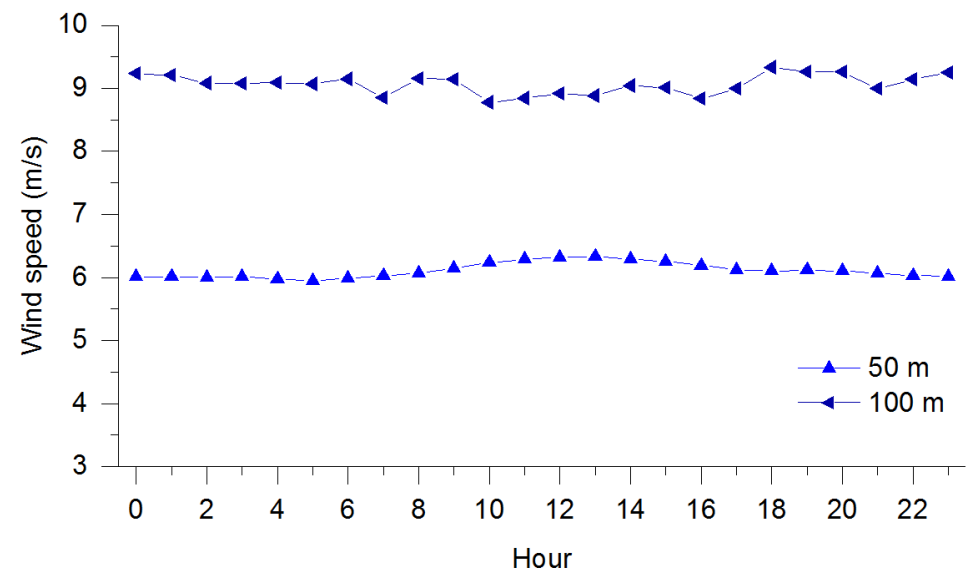

Fig. 6. Daily wind speed profiles at two heights for Jasło

Also, the probability density for the occurrence of higher wind speeds (ranging from 8 to $16 \mathrm{~m} / \mathrm{s}$ ) is considerably higher in case of $100 \mathrm{~m}$. Then, high share of speeds ranging from 0 to $6 \mathrm{~m} / \mathrm{s}$ is visible for the height of $50 \mathrm{~m}$. Consequently, in both cases Weibull distribution has the shape as shown in Fig. 7.

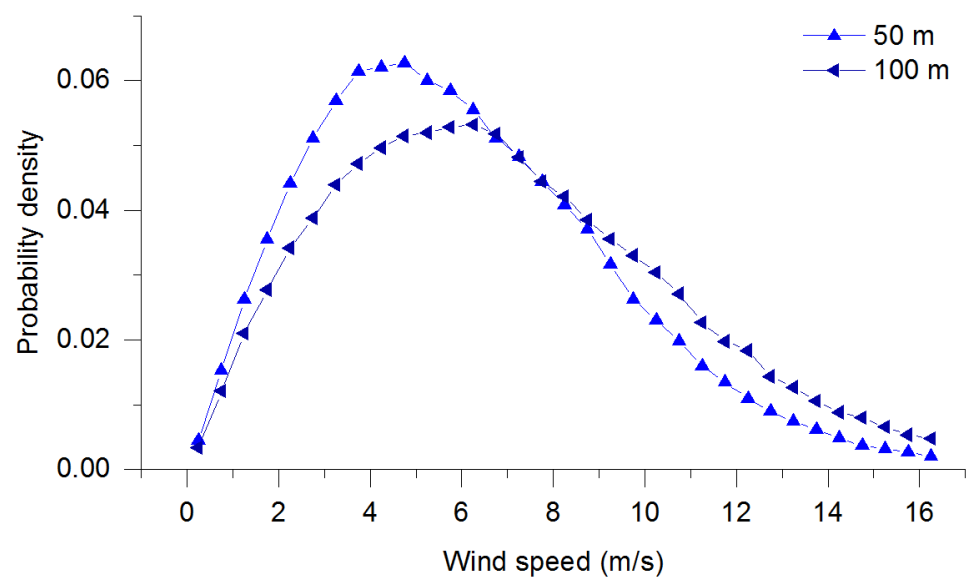

Fig. 7. Weibull wind speed distribution for heights 50 and $100 \mathrm{~m}$ for Jasło.

\subsection{Estimated energy generation in wind turbines}

Based on the analysis of wind resources at different locations, the area in the vicinity of Jasło has been chosen for further considerations. This area is characterised by greatest potential regarding the investment in wind turbines among all discussed locations. The use of four market available wind turbines with parameters specified in Tab. 2 has been discussed for this location. In case of the two turbines, for which tower height remains within range 
from $50 \mathrm{~m}$ to $100 \mathrm{~m}$, wind energy $\mathrm{E}(\mathrm{h}$ ) has been recalculated (eq. 5) for the appropriate height h.

where:

$$
E(h)=E_{0} \cdot\left(\frac{h}{h_{0}}\right)^{3 \alpha}
$$

$\mathrm{E}_{0} \quad$ - wind energy at the height of $\mathrm{h}_{0}$,

$\mathrm{h}_{0}$ - reference height,

$\alpha-$ coefficient dependent on terrain roughness.

Table 2. Energy generation for selected wind turbines

\begin{tabular}{|c|c|c|c|}
\hline Turbine & $\begin{array}{c}\text { Nominal power } \\
{[\mathbf{k W}]}\end{array}$ & $\begin{array}{c}\text { Tower height } \\
{[\mathbf{m}]}\end{array}$ & $\begin{array}{c}\text { Rotor diameter } \\
{[\mathbf{m}]}\end{array}$ \\
\hline WT1 & 2,000 & 85 & 71 \\
\hline WT2 & 1,500 & 80 & 77 \\
\hline WT3 & 2,050 & 100 & 92.5 \\
\hline WT4 & 2,500 & 100 & 90 \\
\hline
\end{tabular}

The amount of possible electric energy yield when using wind turbines according Table 2 is shown in Fig. 8. As we can see, the most favourable solution is to use the wind turbine no. 4. It allows production of ca. $6.75 \mathrm{GWh}$ of electric energy per year.

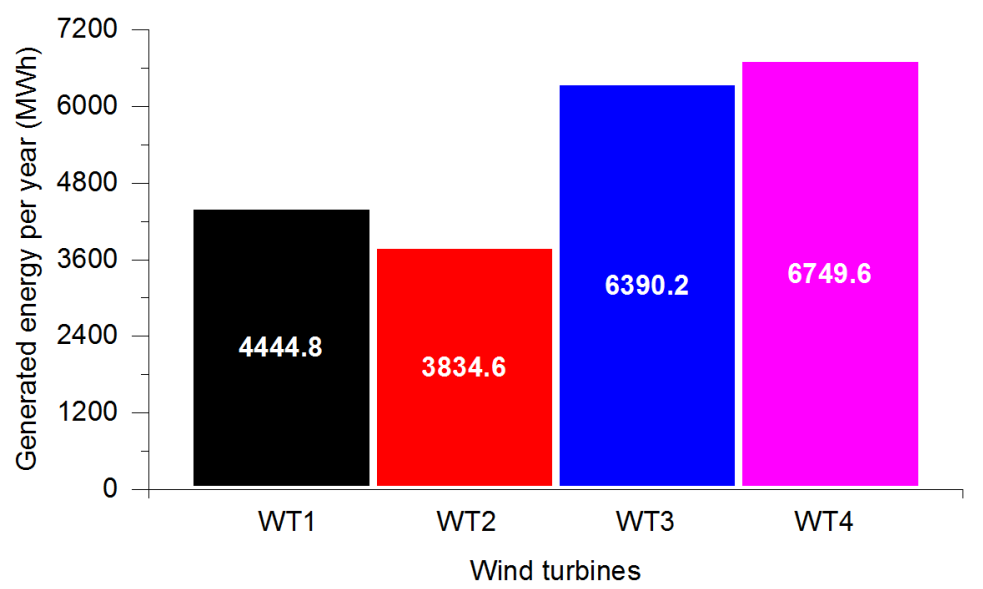

Fig. 8. Amount of energy generation for selected turbines

Assuming that the cost of wind farm construction in Poland is ca. 7 million PLN per $1 \mathrm{MW}$ of installed power, and the price per a unit of electric energy produced by wind power plant (with installed power exceeding $1 \mathrm{MW}$ ) is $385 \mathrm{PLN} / \mathrm{MWh}$, it is possible to approximate the values of the indexes: SPBT (Simply Pay Back Time), IRR (Internal Rate of Return) and NPV (Net Present Value). These calculations also take into account operating costs (land lease costs, wind farm servicing and management, energy balancing costs, insurance and the costs of energy for own purposes), which are assumed to reach the level of ca. $10 \%$ of the revenues. The values of economic indexes calculated for the assumptions specified above are as follows: $\mathrm{SPBT}=7.4$ years, NPV $=0.746$ million PLN (for considered period of 10 years), and IRR $=7.1 \%$.

Calculations regarding ecological effect can be carried out parallel to the economic calculations. In general, ecological effect can be described as the volume of pollution not discharged into the environment due to operation of new equipment being the subject of the 
investment. The volume of emission avoided $e$ per one year can be expressed in the most general way using the formula (6):

where:

$$
e=\sum E \cdot w_{e, i}
$$

E - the volume of produced electric energy, MWh

$\mathrm{W}_{\mathrm{e}, \mathrm{i}} \quad$ - emission factor of "i" pollution, $\mathrm{kg} / \mathrm{MWh}$

In case of construction of wind power plant with turbine no. 4, emission volumes computed in this way are respectively (compared to a typical coal power plant): $\mathrm{e}_{\mathrm{CO}}=\mathrm{ca} .28$ $\mathrm{Mg}, \mathrm{e}_{\mathrm{CO} 2}=$ ca. $60181 \mathrm{Mg}, \mathrm{e}_{\mathrm{NOx}}=$ ca. $9 \mathrm{Mg}, \mathrm{e}_{\mathrm{SO} 2}=$ ca. $46 \mathrm{Mg}$ and $\mathrm{e}_{\text {dust }}=\mathrm{ca} .84 \mathrm{Mg}$.

\subsection{Simulations of the hybrid wind-diesel power plant in TRNSYS}

Due to the variability in the amount of the energy generated in wind turbines, it is necessary to preserve the capacity e.g. in gas and water peaking power plants. During conducted simulations, diesel electricity generator and DEGS dispatch controller have been used to adapt the number of running engines to a given electrical load which is partly met by Wind Turbines (see Fig. 8).

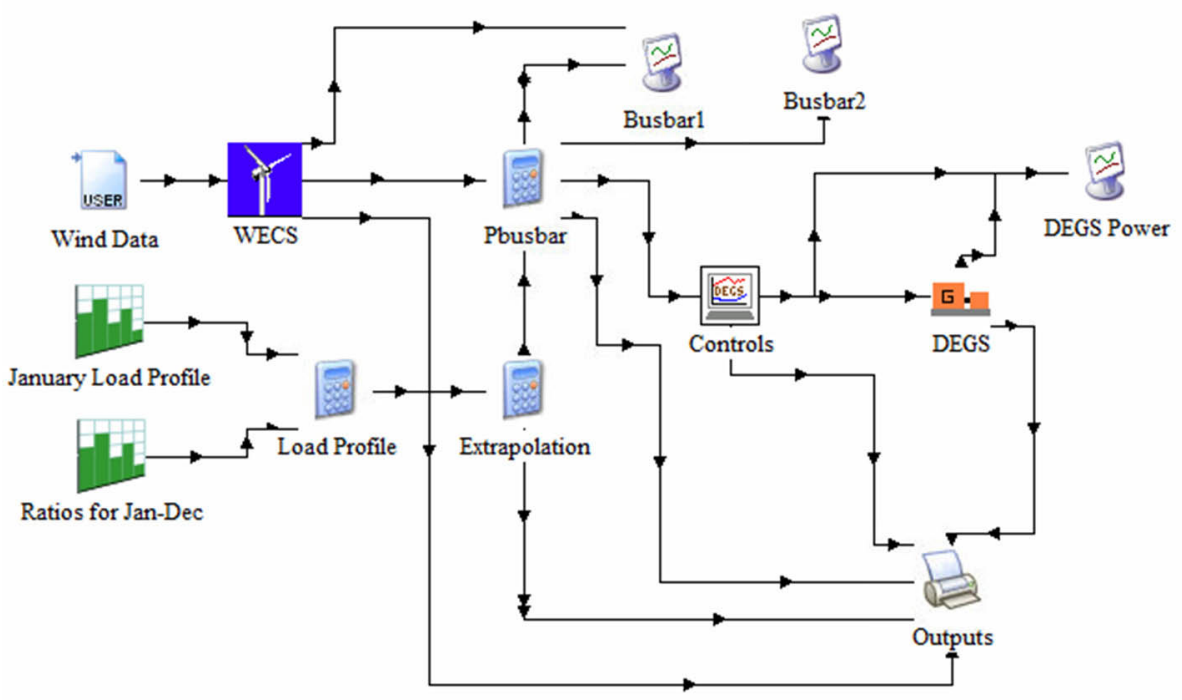

Fig. 9. TRNSYS simulation diagram

The simulations were conducted using wind data for the vicinity of Jasło (wind speed measured at a level of $100 \mathrm{~m}$ ) as an input, $500 \mathrm{~kW}$ wind turbine(s) and $300 \mathrm{~kW}$ diesel generator. The simulation results, shown in Fig. 10, show that in case of using the off-shore systems it is necessary to store energy and use peaking energy source (e.g. diesel generator). The same situation is in the case of on-shore systems connected to the grid, where shortage of energy is met by conventional power plants. The width of peaks characteristic for diesel generator working time changes depending on installed power of the turbines. 


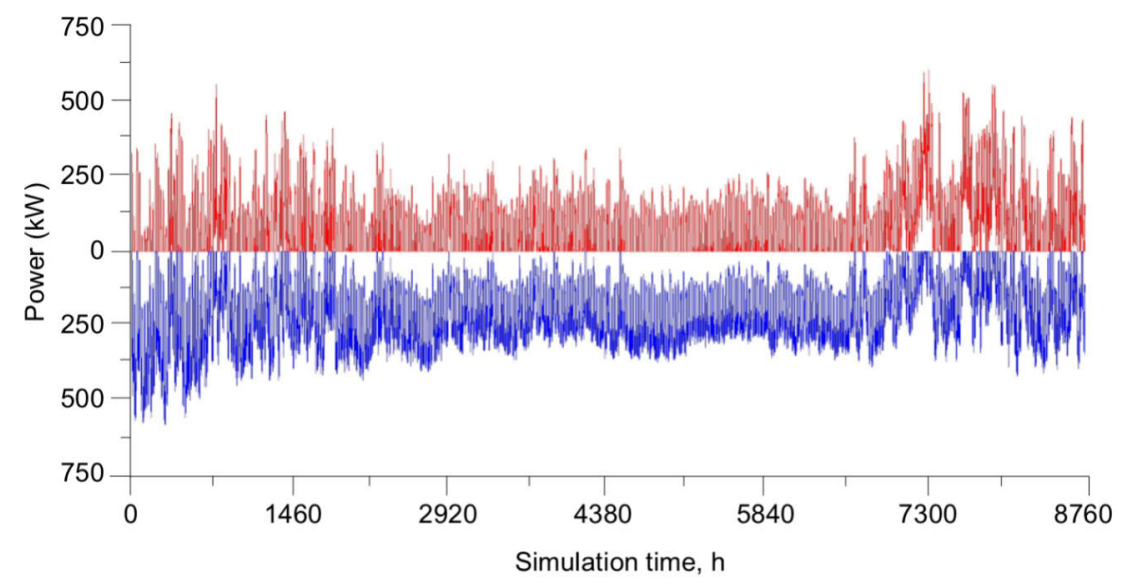

Fig. 10. Results of simulations conducted in TRNSYS.

\section{Conclusions}

Results of measurements conducted in four selected locations show that the selected regions of Małopolskie, Świętokrzyskie and Podkarpackie Voivodeships mostly have quite good wind conditions. The average monthly wind speed is about $5-6 \mathrm{~m} / \mathrm{s}$ at the height of $50 \mathrm{~m}$ in case of three of four considered locations (the vicinity of Sandomierz, Jasło and Leżajsk). Lower wind speed has been measured for location near Gromnik. Taking into account the most promising location (close to Jaslo) we can observe that average wind speed in case of the height of $100 \mathrm{~m}$ is ca. $48 \%$ higher than the speed measured at the height of $50 \mathrm{~m}$. It ranges within $8-11 \mathrm{~m} / \mathrm{s}$ (considering average monthly speed values). Depending on the type of considered wind turbine, it is possible to generate up to $6.8 \mathrm{GWh}$ of electricity in the selected location. Due to high instability of energy production in wind turbines, it is necessary to reserve the capacity in gas and water peaking power plants.

\section{Acknowledgements}

The work has been completed as part of the statutory activities of the Faculty of Energy and Fuels at the AGH University "Studies concerning the conditions of sustainable energy development"

\section{References}

1. T. Mirowski, E. Mokrzycki, R. Ney, Energetyka wiatrowa - stan obecny i szanse rozwoju (Wydawnictwo IGSMiE PAN, Krakow, 2015)

2. M. Donatelli, G. Bellocchi, E. Habyarimana, R. Confalonieri, F. Micale, Comput. Electron. Agr. 69, 165-170 (2009)

3. J. Ephrath, J. Goudrian, A. Marani, Agr. Syst. 51, 377-293 (1996) 